\title{
Public Health Nutrition
}

\section{Volume 19, 2016 ISSN: 1368-9800 journals.cambridge.org/phn}

\section{Publishing, Production, Marketing, and Subscription Sales Office:}

Cambridge University Press

Journals Fulfillment Department

University Printing House

Shaftesbury Road

Cambridge CB2 8BS

UK

\section{For Customers in North America:}

Cambridge University Press

32 Avenue of the Americas

New York

New York 10013

USA

Publisher: Katy Christomanou

\section{Special sales and supplements}

This journal accepts advertising and inserts. We also provide bulk reprints of suitable papers to meet teaching or promotional requirements. The journal also publishes supplementary material including conference proceedings on behalf of academic and corporate sponsors. Please contact Sarah Maddox at Cambridge University Press for further details (email: smaddox@cambridge.org).

\section{Subscription information}

Public Health Nutrition is an international journal published 18 times per year by Cambridge University Press on behalf of the Nutrition Society. The online edition is available at journals.cambridge.org/PHN, with free table of contents alert (upon registration).

\section{Annual subscription rates}

Volume 19, 2016 (18 issues): Internet/print package: £1340/\$2570 Americas only/€2147 EU only Internet only: $\$ 970 / \$ 1840$ Americas only/€1542 EU only

Any supplements to this journal published in the course of the annual volume are normally supplied to subscribers at no extra charge.

Claims for non-receipt of journal issues will be considered on their merit and only if the claim is received within six months of publication. Replacement copies supplied after this date will be chargeable.

Advertising: The Nutrition Society is willing to include advertisements in its journals. However, it will retain the right to make decisions on which advertisements are acceptable and which are not, and will not be obliged to give reasons to prospective advertisers for its decisions. The appearance of an advertisement in the Society's journals does not imply endorsement by the Society. For further details, please contact Cambridge University Press.

Back volumes will be available in due course. Please contact Cambridge University Press for further information.

US POSTMASTERS: Please send address corrections to Cambridge University Press 32 Avenue of the Americas

New York New York 10013 USA

Notes for Authors are available from the publisher at the given address and can be found inside the back cover.

Offprints: The author (or main author) of an accepted paper will receive a free PDF of their paper. Additional offprints are available for a fee and must be ordered at proof stage. No page charges are levied by this journal.

Copyright: As of 1 January 2001 the copyright of all articles submitted to Public Health Nutrition are retained by the authors or their institutions. For articles prior to this date permission for reproduction of any part of the journal (text, figures, tables or other matter) in any form (on paper, microfiche or electronically) should be sought directly from the Society, at: The Editorial Office, The Nutrition Society, 10 Cambridge Court, 210 Shepherds Bush Road, Hammersmith, London, W6 7NJ, UK.

Disclaimer: The information contained herein, including any expression of opinion and any projection or forecast, has been obtained from or is based upon sources believed by us to be reliable, but is not guaranteed as to accuracy or completeness. The information is supplied without obligation and on the understanding that any person who acts upon it or otherwise changes his/her position in reliance thereon does so entirely at his/her own risk. Neither the Society, nor Cambridge University Press accepts responsibility for any trade advertisement included in this publication.

This journal issue has been printed on FSC-certified paper and cover board. FSC is an independent, non-governmental, not-for-profit organization established to promote the responsible management of the world's forests. Please see www.fsc.org for information. Typeset by Macmillan India Limited, Bangalore, India and Printed in Europe by Bell and Bain, Glasgow.

Public Health Nutrition is covered in Science Citation Index Expanded (Web of Science), Current Contents, Agriculture, Biology \& Environmental Sciences, Current Contents, Clinical Medicine, CAB ABSTRACTS ${ }^{\circledR}$, Global Health, Index Medicus ${ }^{\circledR}\left(\right.$ MEDLINE $\left.^{\circledR}\right)$, EMBASE, Excerpta Medica, BIOSIS ${ }^{\circledR}$ Database and CINAHL ${ }^{\circledR}$ Database Public Health Nutrition participates in the following initiatives: HINARI by WHO and AGORA by FAO. 
Public Health Nutrition (PHN) provides a forum for the presentation of original research findings and high quality reviews of key topics, and for discussion of and debate on of current issues and controversies. It also publishes special issues on major topics of interest. Our field includes research, scholarship, and discussions on public health nutrition, that take a population, health promoting and preventive approach. Papers that do not have this emphasis may be directed to more appropriate journals. Potential contributors are encouraged to read the aims and scope of the journal, and to note and follow the guidelines set out below.

\section{Content:}

- Original research findings and scientific reviews are published as full papers usually less than 5000 words, not including the abstract, references, tables, figures and acknowledgements.

- Editorials express the opinion of the journal, as represented by its central editorial team, on topics judged by them to be important. Editorials, including guest editorials, are usually co-ordinated and developed by the editorial team.

- Position papers, including declarations and other statements of policy, may be invited or unsolicited.

- Invited commentaries and book reviews are expressions of opinion on a topical subject. These are commissioned by the members of the editorial team.

- Letters to the Editors are usually in response to material published in PHN. Submissions are sent to the author for comment and, when possible, published together with the author's reply.

Submission: PHN operates an online submission and reviewing system. All manuscripts should be submitted to http:// mc.manuscriptcentral.com/phnutr. Please contact the Editorial Office on phn.edoffice@cambridge.org regarding any other types of submission.

Refereeing: Review articles and articles reporting original research are subject to external review by two or more referees who evaluate manuscripts based on their importance, relevance, and originality. Authors are asked to submit names and contact details (including email address) of up to four potential referees. All other contributions (editorials, position papers, invited commentaries, book reviews, and letters to the Editors) undergo an internal review process by at least two members of the editorial team. Invited commentaries and book reviews may also be checked externally as necessary to avoid technical errors and to improve salience.

Copyright: At the time of acceptance, authors will be asked to provide a completed copy of the 'Licence to Publish' (in lieu of copyright transfer), available at https://www.nutritionsociety. org/. It is the author's responsibility to obtain written permission to reproduce any material (including text and figures) that has appeared in another publication.

Preparation of manuscripts: Please refer to the full Directions to Contributors on our website (http://www.nutritionsociety. org). Manuscripts should be in clear and concise English, and spelling should follow the Oxford English Dictionary. For authors whose native tongue is not English, in-house editorial attention to their contributions will improve clarity. On acceptance, all contributions are subject to editorial amendment to conform to house style. Manuscripts should be prepared in a common word processing package (Word for Windows is preferred) in Times New Roman or other common typeface, prepared with doublespaced text, at least $2 \mathrm{~cm}$ margins, and page and line numbers. Standard abbreviations and SI units must be used.

\section{Disclosure of financial support and any competing}

interests. The submission must include a statement within an Acknowledgements section reporting any competing interests, all sources of funding, and the nature of the contribution of each author to the manuscript. If there are no competing interests, this must be stated. Authors are asked to provide this information during the submission process and should not include it as part of the manuscript to allow for double-blind reviewing.

Arrangement of papers:

1. Title page should include the article title, author(s), affiliation(s), up to eight keywords, one author identified for correspondence (with full postal address, telephone and fax numbers, and email address), and a running title of up to 45 characters. The title page should be submitted online as a separate cover letter, not as part of the manuscript, to enable double-blind reviewing.

2. Abstract should be structured, usually using the following internal headings: Objective, Design, Setting, Subjects, Results, Conclusions. Abstracts should be intelligible without reference to text or figures and should not exceed 250 words.

3. Text should be divided under headings (typically to include Introduction, Methods, Results, Discussion and Conclusions), and sub-headings as appropriate. Conclusions should include recommendations that derive from the research and that are concrete, feasible, and potentially effective. Emphasising that more research is needed is usually not necessary unless there is specific reason to say so. All submissions must include a statement that the research was conducted in accordance with guidelines laid down by the Declaration of Helsinki and approved by an ethics review committee.

4. Acknowledgements (sources of funding, competing interests declaration, authorship responsibilities, acknowledgements) should be provided during the submission process, not as part of the manuscript.

5. References should be in Vancouver style. Please refer to the full Directions to Contributors.

6. Tables should be reduced to the simplest form and should not be used where text or figures give the same information. Each table must be accompanied by a clear and concise caption that is comprehensible without reference to the text. Longer tables may be published online only.

7. Figures should be numbered, and legends should be provided. Each figure, with its legend, should be comprehensible without reference to the text and include definitions of abbreviations.

Proofs: Correspondence and proofs for correction will be emailed to the first named author unless otherwise indicated. The author will receive a PDF proof for checking. It is important that proofs be returned promptly. Authors may be charged for any alterations in excess of $10 \%$ of original setting.

Offprints: The corresponding author will receive a PDF of the published paper free of charge. Offprints are available to purchase and must be ordered before publication. 


\begin{tabular}{l}
\hline Monitoring and surveillance \\
Comparing the nutrition environment \\
and practices of home- and centre-based \\
child-care facilities \\
OJM Martyniuk, LM Vanderloo, JD Irwin, \\
SM Burke and P Tucker
\end{tabular}

Assessment and methodology

The importance of stories in understanding people's relationship to food: narrative inquiry methodology has much to offer the public health nutrition researcher and practitioner G O'Kane and B Pamphilon

Estimating bisphenol A exposure levels using a questionnaire targeting known sources of exposure

SO Nomura, L Harnack and K Robien

\section{Nutrition communication}

Comparative analysis of dietary

guidelines in the Spanish-Speaking

Caribbean

M Fuster

Food and beverage cues in children's television programmes: the influence of programme genre

P Scully, O Reid, A Macken, M Healy,

J Saunders, D Leddin, W Cullen,

C Dunne and CS O'Gorman

\section{Behavioural nutrition}

Investigating sex differences in psychological predictors of snack intake among a large representative sample MA Adriaanse, C Evers, AAC Verhoeven and DTD de Ridder

Dishware size and snack food intake in a between-subjects laboratory experiment E Robinson, F Sheen, J Harrold,

E Boyland, JCG Halford and U Masic

\section{Nutritional epidemiology}

Adherence to complementary feeding recommendations for infants and implications for public health

S Fegan, E Bassett, Y Peng and KS O'Connor

Feeding practices in early life and later intake of fruit and vegetables among Japanese toddlers: the Osaka Maternal and Child Health Study H Okubo, Y Miyake, S Sasaki, K Tanaka and Y Hirota
Snacking between main meals is associated with a higher risk of metabolic syndrome in a Mediterranean cohort: the SUN Project (Seguimiento Universidad de Navarra)

AM Pimenta, M Bes-Rastrollo, A Gea, C Sayón-Orea, I Zazpe, R Lopez-Iracheta and MA Martinez-Gonzalez

Irregular eating of meals in adolescence and the metabolic syndrome in adulthood: results from a 27-year prospective cohort M Wennberg, PE Gustafsson, $P$ Wennberg and A Hammarström

№ association between fish consumption and risk of stroke in the Spanish cohort of the European Prospective Investigation into Cancer and Nutrition (EPIC-Spain): a 13.8-year follow-up study

P Amiano, S Chamosa, N Etxezarreta, L Arriola, C Moreno-Iribas, J-M Huerta,

NEgües, M Guevara, C Navarro,

M-D Chirlaque, M-J Sánchez,

E Molina-Montes, M Requena, J-R Quirós,

M Obón-Santacana, P Jakszyn,

$C$-A González and M Dorronsoro

Acculturation and dietary patterns among residents of Surinamese origin in the Netherlands: the HELIUS dietary pattern study

SM Sturkenboom, LH Dekker,

M Lamkaddem, LA Schaap, JHM de Vries, K Stronks and M Nicolaou

Preferences for food and nutritional supplements among adult people living with HIV in Malawi

S Rodas-Moya, S Kodish, M Manary, $N$ Grede and S de Pee

\section{Community nutrition}

Breast-feeding and complementary feeding practices in the first 6 months of life among Norwegian-Somali and Norwegian-Iraqi infants: the InnBaKost survey

NK Grewal, LF Andersen, D Sellen, A Mosdøl and LE Torheim

Severe iron-deficiency anaemia and feeding practices in young children PC Parkin, J DeGroot, JL Maguire,
Nutrition among men and household food security in an internally displaced persons camp in Kenya KP Singh, SV Bhoopathy, H Worth, H Seale and RL Richmond

\section{Interventions}

Iron+folic acid distribution and consumption through antenatal care: identifying barriers across countries C Sununtnasuk, A D'Agostino and JL Fiedler

Evaluation outcomes of a long-running adult nutrition education programme S Pettigrew, S Moore,

IS Pratt and M Jongenelis

\section{Public policies}

Breastfeeding practices and policies in WHO European Region Member States ATB Bosi, KG Eriksen, T Sobko,

TMA Wijnhoven and J Breda

\section{Corrigendum}

Adolescent dietary patterns are associated with lifestyle and family psycho-social factors - CORRIGENDUM GL Ambrosini, WH Oddy, M Robinson, TA O'Sullivan, BP Hands, NH de Klerk, SR Silburn, SR Zubrick, GE Kendall, FJ Stanley and $U$ Beilin

Cambridge Journals Online For further information about this journal please go to the journal website at: journals.cambridge.org/phn 